\title{
INTOXICAÇÕES EXÓGENAS EM CRIANÇAS E ADOLESCENTES NO ESTADO DO ACRE
}

\author{
Wellington Maciel Melo ${ }^{1}$; Frankllin Ramon da Silva ${ }^{1}$; Deivid Braga da Silva ${ }^{1}$; Carla \\ Nascimento da Costa ${ }^{1}$; Edmilson Pereira Barroso ${ }^{2}$; Eder Ferreira de Arruda ${ }^{3}$ \\ ${ }^{1}$ Bacharel em Enfermagem, Centro Universitário UNINORTE, Rio Branco, Acre. \\ ${ }^{2}$ Bacharel em Biomedicina, Centro Universitário UNINORTE, Rio Branco, Acre. \\ ${ }^{3}$ Docente, Centro Universitário UNINORTE, Rio Branco, Acre.
}

E-mail: wellingtonmelo632@gmail.com

DOI: $10.47094 /$ ICONNACT.2020/27-31

\section{RESUMO}

Introdução: As intoxicações exógenas são um problema de saúde global, principalmente, na fase infanto-juvenil. Objetivo: Descrever o perfil das intoxicações exógenas em crianças e adolescentes no Acre no ano de 2019. Metodologia: Trata-se de um estudo descritivo realizado a partir de dados do Sistema de Informação de Agravos de Notificação que estão disponíveis no site do DATASUS, sendo incluídos todos os casos na faixa etária de 0 a 19 anos. Resultados: Foram registrados 220 casos de intoxicações, sendo 71,8\% das ocorrências no município de Rio Branco, 20,5\% entre crianças de 1 a 4 anos de idade, 53,6\% em adolescentes de 15 a 19 anos e 67,7\% das notificações eram entre indivíduos do sexo feminino. Considerações finais: As intoxicações exógenas em crianças e adolescentes se constituem como uma importante causa de morbidade no estado do Acre, sendo necessário o monitoramento e o planejamento de medidas de controle e prevenção de novos eventos.

Palavras-chave: Assistência Integral à Saúde da Criança e do Adolescente; Epidemiologia; Toxicologia.

\section{INTRODUÇÃO}

As intoxicações exógenas são um problema de saúde global, principalmente, na fase infantojuvenil, com aproximadamente 45 mil mortes anuais e uma incidência de 1,8 a cada 100 mil habitantes (LADEIRA et al., 2018). Segundo dados da Organização Mundial da Saúde (2020), no ano de 2012, as intoxicações exógenas foram à causa de morte de mais de 190.000 pessoas de forma não intencional, sobretudo, em países subdesenvolvidos.

De acordo com a Sociedade Brasileira de Pediatria (2020), vários são os fatores que 
proporcionam a constante exposição das crianças entre 1 e 4 anos de idade a agentes tóxicos, dentre eles: o longo tempo de permanência em casa, a escassa informação dos pais quanto a medidas de prevenção de acidentes domésticos e embalagens não-seguras.

Da mesma maneira, os adolescentes também se configuram como um grupo de risco, pois passam por um período de curiosidade aguçada, que pode levar a experimentação de bebidas alcoólicas e drogas lícitas e ilícitas. Os adolescentes também estão susceptíveis a depressão, que podem desencadear desejo de suicídio, levando a busca de medicamentos como meio para tal, causando intoxicações intencionais (NAKAJIMA et al., 2019).

Dessa forma, as intoxicações exógenas constituem uma das principais causas de acidentes na infância e adolescência. Portanto, é de suma importância descrever o perfil desses agravos em crianças e adolescentes no estado do Acre a fim de proporcionar uma melhor compreensão acerca do tema e possibilitar ações para prevenção e promoção da saúde.

Dado ao exposto, o presente estudo teve como finalidade descrever o perfil das intoxicações exógenas em crianças e adolescentes no Acre no ano de 2019.

\section{METODOLOGIA}

Foi realizado um estudo observacional descritivo, do tipo transversal, com abordagem quantitativa sobre as intoxicações exógenas em crianças e adolescentes no estado do Acre no ano de 2019.

Os dados foram obtidos durante o mês de novembro de 2020 a partir do Sistema de Informação de Agravos de Notificação (SINAN) e estão disponíveis no sítio eletrônico do Departamento de Informática do Sistema Único de Saúde (DATASUS), sendo incluídos todos os casos na faixa etária de 0 a 19 anos.

Foram considerados como casos de intoxicações exógenas, todos os registros classificados pelo diagnóstico que utilizavam os códigos (T36 - T50) do capítulo XX (Causas externas de morbidade e de mortalidade) da Décima Revisão da Classificação Estatística Internacional de Doenças e Problemas Relacionados à Saúde (CID-10).

Os dados acerca das intoxicações exógenas foram analisados de acordo com município de notificação, sexo e faixa etária por meio do programa Microsoft ${ }^{\circledR}$ Office Excel 2016 no qual foram calculadas as frequências absolutas e relativas das variáveis. 


\section{RESULTADOS E DICUSSÃO}

No estado do Acre no ano de 2019 foram registrados 220 casos de intoxicações exógenas em crianças e adolescentes, sendo que $71,8 \%$ das notificações ocorreram no município de Rio Branco $(\mathrm{n}=158)$. Este resultado é superior aos encontrados nos estudos realizados na cidade de Barra do Garças (MT), no período de 2008 a 2013, no qual foram identificadas 125 notificações de intoxicações exógenas, sendo 77 em crianças e 48 em adolescentes (OLIVEIRA; SUCHARA, 2014) e em um Hospital Universitário Regional de Maringá (PR) com indivíduos entre zero a 14 anos, entre os anos de 2006 e 2011, no qual a maior ocorrência foi verificada nos anos de 2007 e 2008, com 128 casos em cada ano e o ano de menor ocorrência o de 2010, com 93 casos, resultando em uma média de 116 internações ao ano (DOMINGOS et al., 2016).

Neste contexto, as intoxicações exógenas entre crianças e adolescentes se configuram como um importante problema de saúde no Acre e em todo o Brasil, em um estudo foi constatado o total de 198.367 notificações, no período de 2010 a 2019, sendo que 3,47\% ocorreram na região Norte (SILVA et al., 2020).

Com relação às faixas etárias, 20,5\% das intoxicações ocorreram em crianças de 1 a 4 anos de idade e 53,6\% em adolescentes de 15 a 19 anos. Do mesmo modo, em uma pesquisa com crianças atendidas na região de Araçatuba (SP), no período de 2010 a 2015, foram verificadas 300 notificações e dentre os menores de 5 anos o grupo com maior frequência de intoxicação notificada foi de crianças de 1 a 2 anos com 34,3\% dos casos (RAMOS et al., 2017). De igual modo, em outro estudo que investigou as notificações de intoxicação exógena em adolescentes no Paraná, no período de 2008 a 2017 se observou uma prevalência de casos na faixa etária de 15 a 19 anos (74,50\%) (QUEIROZ et al., 2020).

De acordo com Oliveira e Suchara (2014), existe diferença entre as circunstâncias que envolvem as intoxicações de crianças e adolescente, os casos em adolescentes ocorreram, principalmente, por tentativa de suicídio e no caso das crianças as intoxicações são acidentais.

No que diz respeito ao sexo, 67,7\% das notificações de intoxicação ocorreram entre indivíduos do sexo feminino no Estado do Acre. Este resultado corrobora com os dados do estudo nacional sobre intoxicações exógenas que identificou o predomínio de casos do sexo feminino (67,25\%) (SILVA et al., 2020). Porém, esse resultado diverge dos encontrados por Domingos et al. (2016) onde o sexo masculino apresentou maior número de internações por intoxicações em todas as faixas etárias e por Silva et al. (2020) em que a maior incidência de casos em Sergipe, no período de 2010 a 2017, ocorreu em indivíduos do sexo masculino $(55,7 \%)$.

No Brasil, as tendências tanto para óbitos quanto para internações hospitalares por intoxicações, apresentam-se ascendentes, em ambos os sexos, embora sejam maiores entre os homens em todas as faixas etárias (SANTOS; BOING, 2018). 


\section{CONSIDERAÇÕES FINAIS}

As intoxicações exógenas em crianças e adolescentes se constituem como uma importante causa de morbidade no estado do Acre, especialmente entre os indivíduos de 15 a 19 anos de idade e do sexo feminino. Portanto, é necessário o monitoramento da frequência dos casos para o planejamento de medidas de controle e prevenção de novos eventos.

\section{PRINCIPAIS REFERÊNCIAS}

DOMINGOS, S. M. et al. Internações por intoxicação de crianças de zero a 14 anos em hospital de ensino no sul do Brasil, 2006-2011. Epidemiologia e Serviços de Saúde, v.25, n.2, p.343-350, 2016.

LADEIRA, R. M. et al. Intoxicações exógenas acidentais em crianças e adolescentes atendidos em um serviço de toxicologia de referência de um hospital de emergência brasileiro. Revista Paulista de Pediatria, v. 38, p.1-8, 2018.

NAKAJIMA, N. R. et al. Análise epidemiológica das intoxicações exógenas no Triângulo Mineiro. Brazilian Journal of Health and Biomedical Sciences, v. 18, n.2, p 1-4. 2019.

OLIVEIRA, F. F S.; SUCHARA, E. A. Perfil epidemiológico das intoxicações exógenas em crianças e adolescentes em município do Mato Grosso. Rev Paul Pediatr, v.32, n.4, p.299-305, 2014.

ORGANIZAÇÃO MUNDIAL DA SAÚDE. Prevenção e gestão de envenenamento. 2020. Disponível em: https://www.who.int/ipcs/poisons/en/. Acesso em 24 nov. 2020.

QUEIROZ, R. O. et al. Caracterização dos casos de intoxicações exógenas em adolescentes no estado do Paraná. Anais do II Congresso de Saúde Coletiva da UFPR. Disponível em: $<$ https://eventos. ufpr.br/csc/csc20/paper/view/4117>. Acesso em: 24 nov.2020.

RAMOS, T. O. et al. Indicadores epidemiológicos das intoxicações exógenas em crianças menores de 5 anos na região de Araçatuba-SP. Revinter, v.10, n.03, p. 86-100, 2017.

SANTOS, G. A. S.; BOING, A. C. Mortalidade e internações hospitalares por intoxicações e reações adversas a medicamentos no Brasil: análise de 2000 a 2014. Cad. Saúde Pública, v.34, n.6, 1-14, 2018.

SILVA, I. S. et al. Aspectos epidemiológicos das intoxicações exógenas em crianças no estado de Sergipe entre 2010 e 2017. Scire Salutis, v.10, n.3, p.51-57, 2020.

SILVA, M. N. et al. Perfil da morbimortalidade de adolescentes por intoxicação exógena no Brasil Research, Society and Development, v. 9, n.10, p.1-25, 2020. 
SOCIEDADE BRASILEIRA DE PEDIATRIA. Intoxicações Exógenas. 2020. Disponível em: https://www.sbp.com.br/especiais/pediatria-para-familias/prevencao-de-acidentes/intoxicacoesexogenas/. Acesso em 24 nov. 2020. 